ROCZNIKI HUMANISTYCZNE

$\frac{\text { Tom LXIX, zeszyt } 6-2021}{\text { ZESZYT SPECJALNY }}$

DOI: https://doi.org/10.18290/rh21696s-5

\title{
AGATA KOMOROWSKA
}

\section{CUANTIFICADOR TODO EN TIEMPOS DEL COVID}

\section{INTRODUCCIÓN}

El decir que la pandemia del coronavirus ha cambiado nuestro mundo para siempre es una obviedad. A diario notamos sus secuelas en distintos ámbitos de la vida, incluido el lenguaje. Por tanto, no es de extrañar que se hayan dedicado a este último aspecto varios artículos divulgativos ${ }^{1}$ y científicos (Kaźmierczak y otros), centrados principalmente en el léxico: la aparición de palabras nuevas (covidiota), vocablos olvidados reinstertados en el lenguaje actual (cuarentena), tecnicismos utilizados fuera de contextos especializados (coronavirus) o nuevas combinaciones con sentido específico (nueva normali$d a d$ ). Hasta se ha acuñado el término de covidioma o coronalengua ${ }^{2}$ (DHLE) para referirse a esos fenómenos lingüísticos pandémicos.

Además de las mencionadas cuestiones léxicas, no parecen menos interesantes los efectos de la COVID en los procesos comunicativos. Se observa un significativo impacto de la pandemia en los mensajes emitidos en la esfera pública, en la que destacan los medios de comunicación y los discursos políticos. Entre las intervenciones políticas llaman la atención aquellas del máximo representante del poder ejecutivo, quien se enfrenta a un reto importante: garantizar el cumplimiento de las soluciones basadas en la restricción

Dr Agata KomorowsKa - adiunkt Zakładu Filologii Hiszpańskiej Instytutu Filologii Romańskiej, Wydział Filologiczny Uniwersytetu Jagiellońskiego; adres do korespondencji: Collegium Paderevianum, Al. Mickiewicza 9A, 31-120 Kraków; e-mail: agata.komorowska@uj.edu.pl; ORCID: https://orcid.org/0000-0003-2663-1209.

${ }^{1}$ Véanse, entre otros, los siguientes artículos destinados al público general en www.revistareplicante.com/las-palabras-de-la-pospandemia; www.efesalud.com/ensalada-semanticade-la-covid-19.

${ }^{2}$ www.rae.es/dhle/covidioma. 
de libertades sin perder el apoyo de la sociedad. ¿Qué elementos lingüísticos seleccionar para conseguir dicha finalidad?

Para examinar esa cuestión, hemos optado por un corpus integrado por todas las intervenciones del presidente del gobierno español Pedro Sánchez, publicadas en la página web oficial y realizadas en el periodo comprendido entre enero y junio de 2020, época de la máxima movilización frente a la crisis sanitaria provocada por el coronavirus COVID-193. En total, los ejemplos extraídos junto con sus contextos comprenden 527.620 caracteres con espacios. Dichas intervenciones incluyen discursos preparados de antemano (comunicación unilateral) y respuestas espontáneas a las preguntas formuladas por periodistas y parlamentarios (comunicación interactiva). Es importante señalar que la mayoría de las comparecencias públicas tiene lugar con el motivo de la declaración o ampliación del estado de alarma.

Lo que llama la atención es la frecuencia con la que se emplean los cuantificadores. Además de los numerales, en múltiples ocasiones se emplean los universales y, especialmente, el cuantificador todo. Nuestra hipótesis es que este recurso no es casual y que se emplea con fines pragmáticos. Nos proponemos comprobarlo centrándonos especialmente en las cuantificaciones que operan sobre entidades personales. Comenzaremos con un breve repaso de las características morfosintácticas y semánticas de la forma todo (§1), $\mathrm{y}$, posteriormente, analizaremos los valores pragmáticos de dicha forma en el corpus $(\S 2)$ dedicando la parte final a las conclusiones.

\section{CUANTIFICADOR TODO}

La cuantificación, tema recurrente en la lógica y en la lingüística, es una operación que "incorpora [...] variables que denotan un elemento indiferenciado de un conjunto" (NGLE 1378). De entre los cuantificadores españoles el operador todo es uno de los más interesantes debido a su comportamiento peculiar (Alarcos Llorach 125), frente a los demás elementos de la misma clase. La explicación de su peculiaridad, así como de sus distintos matices de significado, se debe a razones diacrónicas, tratándose de un cuantificador que sustituye en un momento dado a dos vocablos latinos distintos: omnis y totus para asumir los valores sintácticos y semánticos de ambos (Espinosa Elorza 130-131).

\footnotetext{
${ }^{3}$ Es interesante que el virus no se mencione ni una sola vez en enero y únicamente en dos ocasiones en febrero de 2020 y eso por parte de un periodista y un político de la oposición.
} 
Todo forma parte de los cuantificadores denominados indefinidos por algunos (Alcina Franch y Blecua 640), aunque otros lo consideran como definido ( $N G L E$ 1387). Se incluye dentro del paradigma de los adjetivos, el de los pronombres ${ }^{4} \mathrm{y}$, además, forma parte de varias locuciones adverbiales ${ }^{5}$. Aparece principalmente como miembro del sintagma nominal. Puede situarse tanto en posición prenominal como en posnominal, lo cual caracteriza también a otros cuantificadores, si bien es especial su capacidad de preceder al artículo definido, lo cual, según Alarcos Llorach (125), indicaría que el grupo nominal con todo "no es funcionalmente unitario". Además, puede colocarse en el ámbito del predicado y en varias ocasiones se emplea separado del objeto de su cuantificación, por lo que suele recibir la denominación de cuantificador flotante (Rigau 315).

En cuanto a su significado léxico, expresa el concepto de totalidad con sus distintos matices. Batllori (563-564) lo clasifica semánticamente como cuantificador fuerte frente a los cuantificadores débiles. Gutiérrez-Rexach (154) va más allá y postula que solo los determinantes fuertes son cuantificadores (entre ellos: el artículo determinado, los demostrativos, los posesivos, todo, cada), mientras que no tienen ese valor los determinantes débiles (alguno, ningún, etc.), llamados en tal caso marcadores de cardinalidad.

Según otra nomenclatura semántica, todo es cuantificador universal, junto con cada, cualquier y ambos (Sánchez López 1037) o, más precisamente, universal colectivo (Rigau 332).

Todas las múltiples combinaciones y distribuciones del cuantificador universal en cuestión, así como sus valores semánticos, pueden aprovecharse para conseguir determinados efectos pragmáticos.

\section{VALORES PRAGMÁTICOS DE TODO \\ EN EL DISCURSO POLÍTICO DE EMERGENCIA}

2.1. Según recuerda Llanas Sainz (220), a grandes rasgos el discurso político, con sus diversas formas y subgéneros dependientes del contexto de emisión, no se caracteriza por un lenguaje específico, sino por el uso de determinados elementos léxicos, encaminados a activar asociaciones ideológicas concretas, y de recursos morfosintácticos y pragmáticos subordinados a los fines persuasivos perseguidos por el emisor.

\footnotetext{
${ }^{4}$ Algunos califican todo de sustantivo (Alarcos Llorach 126; Alcina Franch y Blecua 640).

${ }^{5}$ En pocas ocasiones forma parte de las locuciones verbales o conjuntivas.
} 
Si tomamos en consideración los parámetros de cortesía verbal propuestos por Brown y Levinson, el discurso político se fundamenta en el poder, una marcada distancia social y el grado de imposición bajo. Este último punto es evidente, puesto que los actos de comunicación contenidos en las intervenciones políticas son principalmente promesas ${ }^{6}$ y aseveraciones de matiz expresivo, en las que la balanza entre el coste y beneficio (Leech) se decanta a favor del destinatario. Los dos parámetros restantes se disimulan mediante las diversas estrategias discursivas, debido a que los políticos en sus actuaciones públicas tienen como objetivo principal la consecución de votos electorales. Así pues, pese a que los discursos políticos en pocas ocasiones son abiertamente directivos (Searle), sin duda las intenciones comunicativas de sus emisores pueden calificarse de transaccionales (Briz 80), esto es, con un objeto de negociación y una finalidad precisa.

Dentro del género discursivo político, es preciso distinguir las intervenciones realizadas en circunstancias de fuerza mayor, que proponemos llamar discurso político de emergencia. Entre sus finalidades destaca la de demostrar a la opinión pública los intentos emprendidos por los gobernantes con el fin de solventar la situación de crisis, lo cual no sería posible sin la participación y apoyo por parte de la sociedad. El corpus está compuesto precisamente por muestras de ese tipo de discurso, en las que el emisor es Pedro Sánchez en su calidad de jefe del gobierno, mientras que el destinatario es una figura desdoblada. Por una parte, son interlocutores directos los parlamentarios y los periodistas participantes (a veces telemáticamente) en el intercambio de mensajes, pero no se puede olvidar que un emisor político, independientemente del auditorio presente, en última instancia siempre se dirige a sus votantes.

2.2. El cuantificador universal colectivo se emplea en el corpus en todas sus distribuciones y combinaciones, incluidas las poco usadas en el español actual ${ }^{7}$. En la cuantificación de las entidades que denotan personas, prácticamente en todos los casos todo se utiliza en plural, la mayoría de las veces en masculino, si bien, en ocasiones, acompañado de su variante femenina.

Juzgando a partir de las marcas deícticas ${ }^{8}$, todos se refiere principalmente a la primera persona del plural, que en el corpus recibe dos interpretaciones. El nosotros generalizador equivale al emisor y al destinatario general: la

\footnotetext{
${ }^{6}$ Sobre la pragmática de las promesas parlamentarias, véase Kern.

${ }^{7}$ Se registra una ocurrencia de todo pospuesto al sustantivo no definido: «Indicaciones todas que son recomendaciones hechas $[\ldots]$ »

${ }^{8}$ Nótese al margen que las manifestaciones deícticas del emisor y destinatario tiñen el mensaje de subjetivo, siendo la omisión deíctica, tal y como lo demuestra Bień, una de las condiciones para conseguir la objetividad discursiva.
} 
sociedad española y, en ocasiones, todos los afectados por la pandemia, no solo en territorio español $(1,2)$. El nosotros restrictivo engloba al yo del acto comunicativo y, como receptores directos del mensaje, a representantes políticos o autoridades gobernantes ( 3 y 4 ).

(1) Pero necesitamos mucho más: necesitamos el soporte de toda la comunidad. Todos debemos facilitar a los demás la adaptación a este periodo transitorio pero muy difícil. Todos, todos, todos debemos ser conscientes de que podemos ocupar una u otra posición en cada caso.

(2) Las mujeres y los hombres de nuestro tiempo somos herederos de la Ilustración, la razón, el conocimiento científico, con todas sus limitaciones. Todos confiamos en que, pronto, los investigadores den con los fármacos que nos ayuden.

(3) Como presidente del Gobierno de España, he agradecido reiteradamente la positiva respuesta dada por los distintos responsables públicos. La superación de las distancias y los desacuerdos para unir fuerzas en una batalla como la que ahora libramos es algo que nos reconcilia a todos con el ejercicio de la política entendida en su más alta y noble expresión.

(4) Y todos los aquí presentes sabemos que la dependencia, que es el cuarto pilar del Estado del Bienestar?.

Recordemos que el hecho de que nosotros incluya dos papeles discursivos diferentes: "le Locuteur et l'Objet du discours ou encore le Locuteur et l'Allocutaire» (Bogacki 77) suele aprovecharse en el discurso político, en el que, mediante el concepto de exclusión o inclusión, el hablante se identifica, o no, con sus electores o la comunidad internacional (Gelabert 20) ${ }^{10}$. No obstante, el contexto discursivo del corpus (principalmente las particulares circunstancias de emisión de los mensajes, además de determinados elementos lingüísticos) nos indican que en ambos tipos de nosotros empleados por Pedro Sánchez se trata de un plural inclusivo, y nos ayuda a distinguir entre todos + nosotros generalizador y el restrictivo (5) (6) (7).

(5) Todos los españoles vamos a doblegar a esa curva ${ }^{11}$.

(6) El virus se combate y se doblega con sacrificio y con la unión de todos y de todas. [...] Demos lo mejor de nosotros mismos como representantes de la sociedad $^{12}$.

\footnotetext{
${ }^{9}$ Ejemplos 1, 2, 3 y 4: comparecencia el 18 de marzo de 2020 (fecha de consulta: 7 de abril de 2021).

${ }^{10}$ Hasta se ha acuñado un término especial: el nosotros politico, que incluye al destinatario en «un colectivo o un todo superior [...] del que emisor y receptor forman parte» (Fernández Lagunilla 54). Sobre nosotros en la política véase también Komorowska (2016).

${ }^{11}$ Comparecencia el 4 de abril de 2020 (fecha de consulta: 14 de abril de 2021).

${ }^{12}$ Comparecencia el 18 de abril de 2020 (fecha de consulta: 18 de abril de 2021).
} 
(7) $\mathrm{Y}$ en ese sentido animo a que efectivamente todos los ciudadanos en esta semana que empezamos pues lógicamente cumplamos con nuestras normas de manera ejemplar [...]. Aquí no hay un riesgo moral, aquí lo que hay es un objetivo colectivo de toda una sociedad $[\ldots]^{13}$.

La explicación de los usos anteriormente comentados reside en la voluntad del emisor de influir en la percepción de la realidad por parte de su auditorio y, por ende, en sus decisiones. El cuantificador universal con su significado de totalidad y colectividad absoluta, es decir, siendo un elemento lingüístico por el que se transmite el mensaje de no excluir a nadie, apela al sentido de afiliación (Bravo), necesidad predominante en la cultura española (Albelda y Contreras), que implica la solidaridad y confianza. En esos valores se fundamenta la estrategia discursiva del presidente del gobierno en sus intervenciones encaminadas a convencer a los destinatarios de lo indispensable que son las medidas emprendidas, que limitan las libertades democráticas, y de la importancia que reviste la participación activa y estricta de la sociedad en las mismas. Con el fin de evitar las imposiciones directas, el emisor, en lugar de utilizar las formas verbales imperativas, prácticamente inexistentes en el corpus, o perífrasis deónticas, empleadas con moderación, recurre al cuantificador universal colectivo poniendo en valor la solidaridad, tan preciada por sus interlocutores.

El sentido de afiliación se pondera aún más en la construcción formada por todos con la preposición entre, que en combinación con los pronombres personales de primera y segunda persona denota participación y cooperación (Diccionario Panhispánico de Dudas, www.rae.es/dpd/entre). El mismo sentido se desprende de sus frecuentes usos con el cuantificador universal colectivo $(8,9)$.

(8) Si logramos los niveles de movilidad que tenemos durante los fines de semana, que tampoco es que sea una gran diferencia respecto a los días laborables, pero es una diferencia lo suficientemente significativa para poder, entre todos, lograr esa reducción de la movilidad y, en consecuencia, frenar aún más de manera más acusada la transmisión de la pandemia ${ }^{14}$.

(9) Es decir, ese $51 \%$ de la ciudadanía española recuperará una porción mayor de sus vidas gracias al terreno que hemos conquistado, entre todos, frente al virus ${ }^{15}$.

\footnotetext{
${ }^{13}$ Conferencia de prensa el 25 de abril de 2020 (fecha de consulta: 20 de abril de 2021).

${ }^{14}$ Comparecencia el 28 de abril de 2020 (fecha de consulta: 13 de abril de 2021).

${ }^{15}$ Comparecencia el 9 de mayo de 2020 (fecha de consulta: 14 de abril de 2021).
} 
Se hace hincapié en la afiliación también cuando todo cuantifica el nosotros restrictivo para animar a los destinatarios procedentes de los círculos parlamentarios o administrativo- gubernamentales a renunciar a sus intereses particulares y los de sus partidos, uniéndose así a la lucha contra la pandemia (10):

(10) Estoy convencido de que, efectivamente, la única opción eficaz contra el virus es el aislamiento social. Todos nosotros y todas nosotras, con independencia de nuestro color político, estamos convencidos de eso ${ }^{16}$.

En este último ejemplo se aprecia además otro efecto pragmático, el de énfasis puesto en el cuantificador. Normalmente, en la posición reservada en el sintagma nominal exclusivamente para todo, esto es la predeterminante (Camus Bergareche 899), dicho cuantificador no suele destacar, salvo que reciba la entonación adecuada o se repita "quedando así destacado el constituyente al que acompaña" (Suárez Fernández 822). Ello se corresponde con los efectos provocados en la estructura informativa por la redundancia, cuando el objetivo no es presentar información nueva, sino hacer patente su relevancia (Bosque 54).

Asimismo, el refuerzo enfático se consigue empleando en el mismo enunciado más de un cuantificador universal. En el corpus son frecuentes las construcciones que combinan todo con $\mathrm{cada}^{17}$ (11):

(11) [...] sin duda alguna, las medidas de protección colectiva ya sean las medidas de higiene, ya sean las mascarillas, ya sean las medidas de distanciamiento que vienen siendo la tónica habitual en las conductas que ya tenemos todos y cada uno de nosotros ${ }^{18}$.

La anterior expresión obviamente sirve para destacar los valores presentados por ambos universales. La doble cuantificación refuerza una vez más el sentido de afiliación y la solidaridad entre los distintos miembros del colectivo que constituye la variable cuantificada por los dos operadores, acentuando la totalidad del conjunto como tal, y, simultáneamente, de forma individual, sus elementos integrantes. De esta manera, pragmáticamente se apela también al sentido de autonomía, sin excluirse el de afiliación.

En otros fragmentos del corpus dicha referencia a la autonomía se realiza además de forma expresa en el nivel léxico, lo que sirve para emitir un mensaje personal a cada uno de los destinatarios con el fin de animarlos a actuaciones conjuntas (12). En otras palabras, lo individual reviste importancia porque conforma lo colectivo: de la voluntad autonómica depende la fuerza de la afiliación.

\footnotetext{
${ }^{16}$ Comparecencia el 25 de marzo de 2020 (fecha de consulta: 13 de abril de 2021).

${ }^{17}$ Véase más acerca de este universal distributivo en López Palma.

${ }^{18}$ Conferencia de prensa el 25 de abril de 2020 (fecha de consulta: 5 de abril de 2021).
} 
(12) Y hasta que llegue la vacuna o el remedio terapéutico, la victoria sigue dependiendo de todos y cada uno de nosotros y nosotras, de nuestra cautela, de nuestra prudencia, en consecuencia de nuestra responsabilidad individual y colectiva ${ }^{19}$.

La cuantificación universal colectiva con denotación personal no se limita a la primera persona del plural. En el corpus se encuentran múltiples ocurrencias en las que todo actúa en relación con la tercera persona del plural. Algunos de esos casos se deben a razones sintáctico-semánticas: cuando se enumeran varios elementos es preciso utilizar todos (13) para evitar las posibles ambigüedades referenciales.

(13) Como ya dije ayer, no vamos a dejar a nadie atrás, y mucho menos a los más vulnerables, a los mayores, a las familias con menos recursos, [...] A todos ellos les vamos a proteger mientras dure esta crisis ${ }^{20}$.

Nótese que en el fragmento (13) el cuantificador universal ocupa una posición poco usual, esto es, la preverbal, y que, además, el predicado va precedido de un pronombre personal átono, lo cual indicaría que todo asume el papel de foco informativo (Suárez Fernández 829) junto con el pronombre personal tónico.

En otras ocasiones, todos se emplea con fines pragmáticos dimanantes de su significado básico: al emisor le interesa hacer hincapié en la idea de no excluir a nadie. Ello se observa en actos de habla expresivos formulados en tercera o en segunda persona, por los que se pone en valor a personas determinadas (14 y 15).

(14) Quiero dar las gracias a todos los españoles por su ejemplaridad. España ha hecho lo que debe y ahora para todos se abren nuevos horizontes $[\ldots]^{21}$

(15) Todo esto me permite asegurarles, con orgullo, que debemos sentirnos muy orgullosos de los servicios públicos, de los servidores públicos, de todos y cada uno de ellos. Orgullosos de todos y cada uno de los que desempeñan su trabajo en las administraciones y en las instituciones públicas. Orgullosos de todos y cada uno de los funcionarios, funcionarias, del personal público de cada uno de los departamentos $[\ldots]^{22}$.

En el ejemplo (15), el efecto pragmático-discursivo se pondera de nuevo con la repetición del cuantificador todo, acompañado además del universal distributivo.

\footnotetext{
${ }^{19}$ Comparecencia el 23 de mayo de 2020 (fecha de consulta: 15 de abril de 2021).

${ }^{20}$ Véase la ref. 13.

${ }^{21}$ Comparecencia el 21 de marzo de 2020 (fecha de consulta: 9 de abril de 2021).

22 Ibidem.
} 
Obviamente, la cuantificación no se efectúa tan solo respecto de las personas. El operador en cuestión puede actuar en entidades que denotan objetos, fenómenos, espacios o el tiempo. En las excepcionales circunstancias pandémicas, la falta de exclusión y el concepto de totalidad expresados mediante el cuantificador universal colectivo responde a dos expectativas sociales. La primera de ellas es la necesidad de que se justifiquen las medidas planificadas o aplicadas. Para cumplir con tal expectativa, se muestra el alcance total y absoluto de la amenaza (16).

(16) En estos siete días hemos visto cómo todos los países del mundo, uno tras otro, sufrían el embate de la pandemia. Hemos visto como $^{23}$ se cumplían los peores pronósticos y todos se aproximaban a escenarios de auténtica calamidad. Hemos visto como todos los gobiernos, sin excepción alguna, han ido adoptando medidas extremas para proteger la salud de las personas y salvaguardar también sus economías ${ }^{24}$.

La segunda es la de demostrar el alcance total y absoluto de la respuesta a la crisis, lo cual supone un claro beneficio para la sociedad (17) (18):

(17) De igual modo nos aseguramos de que todos los españoles tengan acceso a toda la información y comprobamos que también, de forma transparente y ordenada se ofrece a todas horas información oficial y veraz al conjunto de la ciudadanía ${ }^{25}$.

(18) [...] en España nosotros estamos protegiendo a todos y cada uno de los seres humanos, a todos y cada uno de nuestros compatriotas, tengan la edad que tengan ${ }^{26}$.

En los ejemplos (16), (17) y (18), el efecto pragmático es comparable con el valor de grado sumo, típico para el cuantificador todo cuando opera sobre adjetivos predicados por él (Sánchez López 1103).

\section{A MODO DE CONCLUSIONES}

A partir del análisis del corpus se desprende que en las condiciones sociales extremas de la pandemia de la COVID, el máximo responsable del poder ejecutivo español recurre en sus intervenciones al cuantificador universal todo con denotación personal, provisto de las oportunas marcas deícticas de

\footnotetext{
${ }^{23}$ En el orginal como sin tilde.

${ }^{24}$ Comparecencia el 21 de marzo de 2020 (fecha de consulta: el 9 de abril de 2021).

${ }^{25}$ Ibidem.

${ }^{26}$ Comparecencia el 18 de abril de 2020 (fecha de consulta: 18 de abril de 2021).
} 
primera persona del plural, con el fin de reforzar el sentido de afiliación entre los miembros de la sociedad, así como los representantes de los partidos políticos y autoridades para así conseguir su colaboración en los momentos más difíciles.

Además, se registran múltiples usos orientados a ponderar determinados contenidos, según las necesidades situacionales, aprovechándose igualmente el significado léxico del cuantificador universal colectivo para hacer hincapié en la voluntad e intención de los responsables políticos de no excluir a nadie en las circunstancias críticas amenazantes.

Finalmente, en las cuantificaciones referentes a entidades que no denotan personas se subraya el valor de sumo grado de todo y así se hace patente la máxima amenaza o el máximo esfuerzo por parte de los gobernantes en la lucha contra la COVID19.

En cuanto a los efectos perlocutivos en la sociedad de los mensajes lanzados desde el gobierno español, las encuestas realizadas por encargo de los medios de comunicación ${ }^{27}$ confirman la respuesta positiva de los españoles frente a las duras medidas restrictivas.

\section{OBRAS CITADAS}

Alarcos Llorach, Emilio. Gramática de la lengua española. Espasa, 1998.

Alcina Franch, Juan y José Manuel Blecua. Gramática española. Ariel, 1987.

Albelda Marco, Marta y Josefa Contreras Fernández. «Imagen de afiliación y atenuantes en un análisis contrastivo alemán/español». Estudios sobre lengua, sociedad y cultura en homenaje a Diana Bravo, eds. María Bernal y Nieves Hernández Flores, Acta Universitatis Stockholmiensis, 2009, págs. 7-30

Batllori, Montserrat. «Naturaleza y distribución de los determinantes y modificadores nominales en las lenguas románicas». Sintassi Storica (Atti del XXX Congresso Internazionale della Società di Lingüística Italiana), eds. Paolo Ramat y Elisa Roma, Bulzoni, 1998, págs. 547-566.

Bień, Janusz. «Recursos de objetividad discursiva en algunos lenguajes funcionales». Itinerarios. Revista de estudios lingüísticos, literarios, históricos y antropológicos, ${ }^{\circ}{ }^{\circ} 23,2016$, págs. 15-34.

\footnotetext{
${ }^{27}$ En la edición de El País de 18 de abril de 2020 se indica que "Un 79,2\% apoya mucho o bastante la extensión del estado de alarma y llegan al 74\% quienes están de acuerdo en la prohibición de hacer deporte al aire libre o salir a dar un paseo. Pese a la polémica sobre el confinamiento absoluto de los niños, un $72,4 \%$ está a favor de mantenerlo". Aunque, eso sí, la mayoría considera que el gobierno pudo haber actuado antes (www.elpais.com/espana/2020-04-18/los-ciudadanos-priman-la-salud-sobrela-economia-y-apoyan-el-rescate-social.html).
} 
Bogacki, Christophe. «A propos du fonctionnement des pronoms en français". Analyse et synthèse dans les langues romanes et slaves, eds. Harro Stammerjohann, Gunter Narr Verlag, 1991, págs. $75-81$.

Bosque, Ignacio. «Interpretaciones de la redundancia en la gramática y en el léxico». Studia Iberystyczne, N. ${ }^{\circ} 19,2020$, págs. 27-60.

Briz Gómez, Antonio. «Cortesía verbal codificada y cortesía verbal interpretada en la conversación». Pragmática sociocultural: estudios sobre el discurso de cortesía en español, eds. Diana Bravo y Antonio Briz Gómez, Ariel, 2004, págs. 67-94.

Bravo, Diana. «¿Imagen positiva vs. Imagen negativa? Pragmática socio-cultural y componentes de face». Oralia. Análisis del discurso oral, N. ${ }^{\circ} 2,1999$, págs. 155-184.

Brown, Penelope y Stephen Levinson. Politeness. Some Universals in Language Use. Cambridge UP, 1987.

Camus Bergareche, Bruno. «Cuantificadores I. Los cuantificadores propios». Sintaxis histórica de la lengua española. Segunda parte: la frase nominal, coord. por Concepción Company Company, Universidad Nacional Autónoma de México/Fondo de Cultura Económica, vol. 2, 2009, págs. $881-960$.

Espinosa Elorza, Rosa María y Carlos Sánchez Lancis. «Cuantificadores indefinidos en la General Estoria (Tercera Parte)». Revista Española de Lingüística, vol. 36, N. 1, 2006, págs. 127-156.

Fernández Lagunilla, Marina. La lengua en la comunicación política I: El discurso del poder. Arco/Libros, 1999.

Gelabert, Jaime J. «La deixis espacio-temporal en el lenguaje parlamentario español contemporáneo». Círculo de lingüística aplicada a la comunicación, N. ${ }^{\circ} 26,2006$, págs. 17-52.

Gutiérrez-Rexach, Javier. La semántica de los indefinidos. Visor, 2003.

Kern, Beate. «La promesa atenuada en el discurso parlamentario español». Estrategias atenuantes en géneros discursivos del español. Interfaz semántico-pragmática, Número especial de Spanish in Context, ed. Marta Albelda Marco, N. ${ }^{\circ}$ 15:2, 2018, págs. 177-197.

Kaźmierczak, Marcin, María Teresa Signes Signes y Cintia Carreira Zafra, editores. Pandemia y resiliencia: aportaciones académicas en tiempos de crisis. Universidad de Navarra, 2020.

Komorowska, Agata. «Pragmática del discurso electoral y el uso de nosotros». Études sur le texte dédiées à Halina Grzmil-Tylutki, eds. Joanna Górnikiewicz, Barbara Marczuk y Iwona Piechnik, Biblioteka Jagiellońska, 2016, págs. 121-134.

Leech, Geoffrey. Principles of Pragmatics. Longman, 1983.

Llamas Saíz, Carmen. «Discurso político». Enciclopedia de las Ciencias Morales y Políticas para el siglo XXI. Ciencias Políticas y Jurídicas (con especial referencia a la sociedad pos-covid-19), ed. Benigno Pendás, prol. Miguel Herrero de Miñón, Academia de Ciencias Morales y Políticas: Boletín Oficial del Estado, 2020, págs. 220-222.

López Palma, Helena. «Las oraciones distributivas: la gramática de cada». Dicenda: Estudios de lengua y literatura españolas, N. ${ }^{\circ}$ 4, 1985, págs. 57-84.

Real Academia Española/Asociación de Academias de la Lengua Española. Nueva gramática de la lengua española (=NGLE). Espasa Calpe, 2009.

Real Academia Española. Diccionario histórico de la lengua española (DHLE). 2013-, www.rae.es/dhle. 
Rigau, Gemma. «La estructura del sintagma nominal: los modificadores del nombre». Gramática descriptiva de la lengua española, dirs. Ignacio Bosque y Violetta Demonte, V., 1999, págs. 311-362.

Searle, John. Actos de habla: ensayo de la filosofía del lenguaje. Traducido por Luis M. Valdés Villanueva, 1969. Cátedra, 1986.

Suárez Fernández, Mercedes. «El comportamiento pragmático del cuantificador todo/s en castellano medieval». Cum corde et in nova grammatica: estudios ofrecidos a Guillermo Rojo, eds. Tomás Jiménez Juliá, Belén López Meirama, Victoria Vázquez Rozas, y Alexandre Veiga, Universidade de Santiago de Compostela, 2012, págs. 819-830.

\section{CORPUS}

www.lamoncloa.gob.es/presidente/intervenciones/paginas/index.aspx.

\section{CUANTIFICADOR TODO EN TIEMPOS DEL COVID}

$$
\text { Resumen }
$$

El inesperado desarrollo de la pandemia del coronavirus exigió que las sociedades del mundo contemporáneo se adaptasen a normas nuevas, no en pocas ocasiones significativamente limitativas para las libertades cívicas. La obligación de informar y tomar decisiones respecto de tales restricciones corresponde a los gobernantes, si bien, por naturaleza, el hecho de imponer cualquier medida a sus potenciales votantes puede provocar en los mismos una actitud de rechazo hacia el político en cuestión, aún siendo tales drásticas soluciones, hasta cierto punto, comprensibles por razones de fuerza mayor. Desde el punto de vista de la pragmática del discurso político, es, por tanto, esencial seleccionar los pertinentes recursos lingüísticos con vistas a conseguir los objetivos comunicativos planteados, sin desanimar al receptor del mensaje.

En las intervenciones oficiales del presidente del gobierno español del periodo comprendido entre enero y junio de 2020 , esto es la época correspondiente al desarrollo más dramático de la pandemia, llama la atención una importante acumulación de expresiones cuantificativas, en particular, el cuantificador universal colectivo todo. Así, en el presente artículo se analizan los distintos usos de dicho elemento lingüístico, dimanantes de las estrategias discursivo-pragmáticas aplicadas por el emisor.

Palabras clave: discurso político; pragmática; expresiones cuantificativas; cuantificador universal.

\section{UŻYCIE KWANTYFIKATORA TODO W CZASIE PANDEMII COVID-19}

$$
\text { Streszczenie }
$$

Niespodziewany rozwój pandemii koronawirusa wymógł na społeczeństwach współczesnego świata dostosowanie się do nowych zasad, nierzadko znacząco ograniczających swobody obywatelskie. Informowanie oraz podejmowanie decyzji w sprawie ograniczeń to obowiązek rządzących. Niemniej z natury rzeczy narzucanie potencjalnym wyborcom czegokolwiek może skutkować ich 
zniechęceniem do danego polityka, mimo że do pewnego stopnia drastyczne rozwiązania są zrozumiałe w obliczu działania siły wyższej. Zatem z punktu widzenia pragmatyki dyskursu politycznego istotne jest takie dobranie środków językowych, aby osiągać zamierzone cele komunikacyjne, nie zrażając przy tym odbiorcy przekazu.

W oficjalnych wystąpieniach premiera hiszpańskiego rządu, obejmujących okres od stycznia do czerwca 2020 roku, czyli przypadających na czas najbardziej dramatycznego przebiegu pandemii, zwraca uwagę nagromadzenie wyrażeń kwantyfikujących, a w szczególności zbiorowego kwantyfikatora uniwersalnego todo. W artykule analizie poddane zostają różne użycia tego elementu językowego wynikające z zastosowanych przez nadawcę strategii dyskursywno-pragmatycznych.

Słowa kluczowe: dyskurs polityczny; pragmatyka; wyrażenia kwantyfikujące; kwantyfikator uniwersalny.

\section{THE QUANTIFIER TODO IN THE TIME OF COVID-19}

\section{Su m mary}

The sudden onset of the Coronavirus pandemic created the need for contemporary societies to adjust quickly to new rules that frequently limit our civil rights. Governments are obliged to take decisions and inform society of such. On the other hand, imposing unpopular rules on potential voters can result in a loss in popularity that can be devastating for a politician. This is true even in the face of a force majeure. Therefore, from the point of view of the pragmatics of political discourse it is imperative to choose those linguistic devices that would allow communicative goals to be achieved while not compromising the speaker

In the official speeches of the Spanish Prime Minister that took place between January and June 2020 and which coincided with the most dramatic period of the pandemic, the frequency of the use of quantitative expressions, especially of the collective universal quantifier todo, is significant. In this paper we will analyse various uses of this linguistic expression that arise from the discursive pragmatic strategies employed by the speaker.

Keywords: political discourse; pragmatics; quantifier expressions; universal quantifier. 